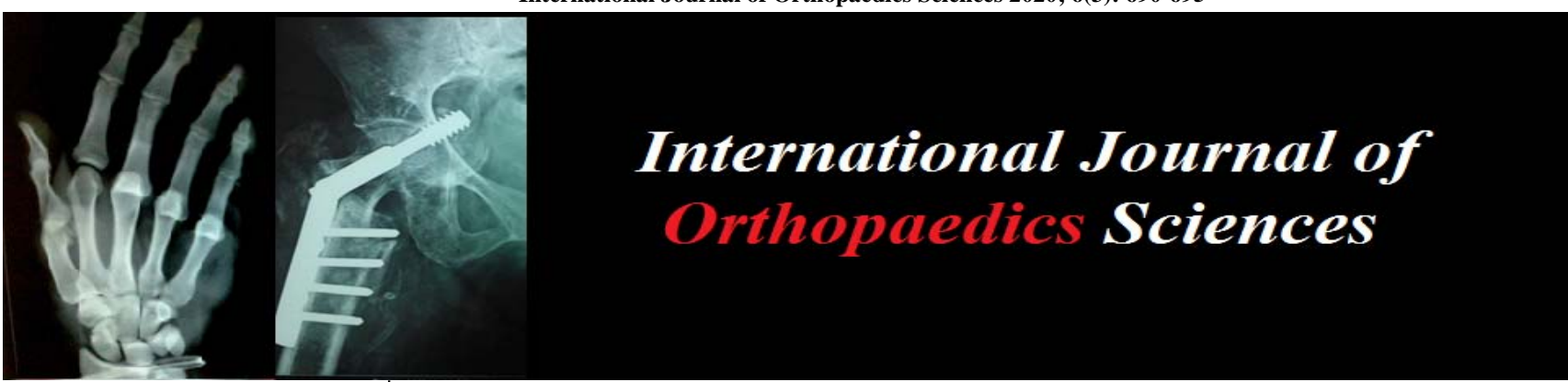

E-ISSN: 2395-1958

P-ISSN: 2706-6630

IJOS 2020; 6(3): 690-695

(C) 2020 IJOS

www.orthopaper.com

Received: 20-05-2020

Accepted: 10-06-2020

Vidisha Kulkarni

Department of Orthopaedics

P.G.I. Swasthiyog Prathishthan

Miraj, India

Nikhil Lambat

Department of Orthopaedics

P.G.I. Swasthiyog Prathishthan

Miraj, India

Tejas Patil

Department of Orthopaedics

P.G.I. Swasthiyog Prathishthan

Miraj, India

Shreya Joshi

Department of Orthopaedics

P.G.I. Swasthiyog Prathishthan

Miraj, India

Shrinivas Jadhav

Department of Orthopaedics

P.G.I. Swasthiyog Prathishthan

Miraj, India

Vijay Dattu

Department of Orthopaedics

P.G.I. Swasthiyog Prathishthan

Miraj, India
Corresponding Author: Dr. Nikhil Lambat

Department of Orthopaedics P.G.I. Swasthiyog Prathishthan Miraj, India

\section{A study on functional outcome of radial head arthroplasty in comminuted radial head fracture}

\author{
Vidisha Kulkarni, Nikhil Lambat, Tejas Patil, Shreya Joshi, Shrinivas \\ Jadhav and Vijay Dattu
}

DOI: https://doi.org/10.22271/ortho.2020.v6.i3k.2270

Abstract

Introduction: Excision is not a suitable treatment for all comminuted fracture of the radial head. In elbow instability can be predicated, radial head arthroplasty is more effective. So the aim of this paper is to study of functional outcome of radial head arthroplasty in comminuted radial head fracture (Modified masons type III and type IV)

Materials and Method: From April 2018 to April 2020, radial head arthroplasty with radial head prosthesis were performed in 30 patients. There were 12 female and 18 male with mean age of 40.3 years. Total no. of patients of right side were 16 and left side were 14 . The follow-up was at $1^{\text {st }} 3^{\text {rd }}$, $6^{\text {th }}$ months. Fractures of the radial head have been classified by Modified Mason classification. The indications for a radial head arthroplasty were type III fractures in 22 cases, type IV fractures in 8 cases, and comminuted radial fracture associated with disruption of the lateral collateral ligament (LCL) in 5 cases, disruption of the medial collateral ligament (MCL) in 2 cases, elbow dislocation with LCL and MCL disruption in 8, olecranon fracture in 2 cases. Patients were assessed postoperatively and on followup at $1^{\text {st }}, 3^{\text {rd }}, 6^{\text {th }}$ months based on Mayo Elbow Performance Index (MEPI) Score.

Results: Results of the study based on MEPI score, out of 30 cases, 20 cases had excellent results, 8 cases had good results, 1 case had fair result, and 1 case had poor result. Out of 30 cases 28cases had no complications, 1 case had CRPS, and 1 case had Elbow joint stiffness.

Conclusion: Radial head arthroplasty can be used successfully with most of excellent results for treatment of Comminuted radial head fracture (The Modified Mason classification type III and IV radial head fractures).

Keywords: Radial head arthroplasty, radial head prosthesis, comminuted radial head fractures, Radial head replacement

\section{Introduction}

The Fractures of the radial head account for $33 \%$ of all fractures of the elbow joint ${ }^{[1]}$, among all most are simple to treat, but comminuted fractures pose a particular problem and mostly associated with instabilities. The most common mechanism of injury is due to an axial load on the pronated and extended forearm. The radial head provides stability to the elbow and forearm by acting as a secondary stabilizer to valgus instability of the elbow, and act as the primary stabilizer being the medial collateral ligament (MCL) and by providing stability to the distal radial ulnar joint to assist the forearm in resisting axial forces and enhancing grip strength ${ }^{[2,3]}$.

There are various pattern of complex injury that includes a fracture of the radial head. These patterns include (i) fracture of radial head associated with rupture of MCL (ii) concomitant fractures of the radial head and capitulum (iii) posterior dislocation of the elbow with fracture of the radial head (iv) posterior dislocation of the elbow with fracture of the radial head and coronoid process (the so-called terrible triad of the elbow) (v) posterior Monteggia fractures including posterior olecranon fracture-dislocations and (vi) Essex-Lopresti lesions and variants ${ }^{[4]}$. The most common injury in comminuted radial head fracture associated with damage to lateral collateral ligament $(51 \%)^{[5]}$. The Conservative management in those pattern 
of fracture leads to poor results, and internal fixation is seldom practical. ${ }^{[6]}$ Excision of the radial head for an isolated comminuted fracture without instabilities can give good longterm results, ${ }^{[7,8]}$ but when such a fracture is associated with other destabilizing injuries to the elbow joint, then excision is not an appropriate treatment. ${ }^{[9]}$ In such destabilizing injuries like posterior dislocation of the elbow, with or without coronoid process fracture, rupture of the medial collateral ligament, and disruption of the distal radio-ulnar joint. For these type of injuries, a radial head replacement arthroplasty better option rather than excision, it will help to restore stability. [10, 11] The purpose of this study is functional outcome of radial head arthroplasty with radial head prosthesis for comminuted radial head fracture (Modified Masons classification type III and IV radial head fractures).

\section{Materials and Method}

A prospective interventional study was undertaken in the Department of Orthopaedics in Post Graduate Institute of Swasthiyog Pratishthan Miraj, from April 2018 to April 2020. Patients with Comminuted radial head fracture (Modified Masons classification type III and IV) admitted to the tertiary care hospital were included in this study after obtaining the informed, written and video consent. Clearance from institutional ethics committee was obtained. Thirty patient with mean age 40.3 with comminuted radial head fracture (Modified Masons classification type III and IV)who were undergoing surgery of radial head arthroplasty admitted to the hospital constituted the study sample.

\section{Inclusion criteria}

1. Modified Mason classification type III and IV fractures.

2. Closed fractures.

3. Age of patient 20 years and more.

4. Presentation within 2 weeks

5. Those who gave consent for the study.

\section{Exclusion criteria}

1. Modified Mason Classification type I and type II fracture.

2. Open fractures.

3. Patients with age $<20$ years.

4. Active infection anywhere in the body.

5. Patient having a neurological and psychological disorder.

6. Those who refused to give consent for the study.

\section{Preoperative}

On admission, a detailed evaluation of the mode of trauma, mechanism of injury and the complaints of the patients were noted. The patients were evaluated for clinical examination including swelling, deformity, skin condition, and general examination. The plain Radiographs include anteroposterior and lateral views of affected limb elbow joint were taken to confirm the fracture. Then CT scan was done to confirm The Modified Masons Classification type and for the planning of surgery. The primary treatment, immobilization was given in the form of above elbow posterior slab. All routine investigations were done. Surgical fitness was obtained from General physician prior to surgery.

\section{Operative}

After informed, written and video consent, patients were taken for surgery. The operation was performed by 1senior surgeon, 1 junior surgeon under general or regional anesthesia. Supine position was given to the patient. Those patients who came with elbow dislocation, in those cases elbow joint reduced under anesthesia. After routine preparation, painting and draping, Kaplan's approach was made to expose the radial head. The fractured radial head was excised and all loose bony pieces removed and care taken not to leave any fragment in the elbow joint. Copious joint irrigation was performed to remove all loose intraarticular debris. Then after removal of the radial head, elbow instability was checked. Valgus, Varus and axial stress tests were performed using an image intensifier to evaluate the competency of the MCL, LCL and interosseous ligament. A radial head prosthesis was used. This device has different head diameter with stem, which allows for a close enough approximation to normal anatomy. The different head heights accommodated for the extension of fractures into the proximal neck and also accounted for observed variability in head height. The broken radial head were reassembled on the table to ensure that the whole head had been resected and to choose the approximate size of the prosthesis. A very small amount of radial neck was resected at a right angle to the medullary canal of the radial neck. The appropriate diameter and height of radial head implant were selected for trial implantation. The medullary canal of the radial neck was gently reamed using the hand reamers. Then rasp was used to smoothen the neck cut, ensuring that it was at $90^{\circ}$ to the neck and the trial radial head prosthesis. The diameter, height, and congruency of the prosthesis were assessed visually with the help of image intensifier. The head had to reach the limit between the trochlear notch and the radial notch of the ulna. Checked for the flexion and extension movement. The trial prosthesis was removed and the final implants were inserted. After radial head replacement, the annular ligament was repaired. The patient with associated injury like LCL, MCL injuries the ligaments were repair, some patients with olecranon fracture were treated. Then checked for stability of the joint. Closure was done in layers, tourniquet deflated. Dressing was done. Postoperative X-ray was taken.

\section{Post-operative and physiotherapy}

Dressing was done every alternate day till suture removal. Physiotherapy was started from the next day of surgery, started with active flexion and extension exercises throughout a full range of motion. The arm pouch was worn during the whole day between exercises. In patients with associated ligamentous injuries, the elbow was maintained in $90^{\circ}$ in posterior above elbow slab till 3 weeks after surgery. Active flexion and extension exercises throughout a full range of motion were started after 3 weeks.

The patients were followed up in outpatient department at $1^{\text {st }}$ month, $3^{\text {rd }}$ month and $6^{\text {th }}$ month. Physiotherapy was continued. At follow-up, patients were examined clinically and radiologically. The patients were assessed on follow-up based on Mayo Elbow Performance Index (MEPI) Score.

The data thus obtained was entered in a pre-designed proforma and entered in to the excel sheet. The data was analyzed using Statistical Package for Social Sciences (SPSS vs 20).

\section{Results}

A total of 30 patients constituted the sample size. All are operated for radial head arthroplasty. The patients were followed for 6 months postoperatively and assessed by using the Mayo elbow performance index score. The follow-up rate was $100 \%$ and there was no mortality in our study. 
Table 1: Socio-demographic characteristics of the study group

\begin{tabular}{|c|c|c|c|}
\hline Criteria & & No. Of Patient & Percentage \\
\hline \multirow{4}{*}{ Age } & $25-35$ & 10 & $33.33 \%$ \\
\cline { 2 - 4 } & $36-45$ & 9 & $30 \%$ \\
\cline { 2 - 4 } & $46-55$ & 11 & $36.66 \%$ \\
\cline { 2 - 4 } & Total & 30 & $100 \%$ \\
\hline \multirow{3}{*}{ Sex } & Male & 18 & $60 \%$ \\
\cline { 2 - 4 } & Female & 12 & $40 \%$ \\
\cline { 2 - 4 } & Total & 30 & $100 \%$ \\
\hline \multirow{3}{*}{$\begin{array}{c}\text { Mide } \\
\text { injury }\end{array}$} & Right & 16 & $53.33 \%$ \\
\cline { 2 - 4 } & Left & 14 & $46.67 \%$ \\
\cline { 2 - 4 } & Total & 30 & $100 \%$ \\
\hline \multirow{3}{*}{$\begin{array}{c}\text { Time of } \\
\text { surgery from } \\
\text { day of trauma }\end{array}$} & Rta & 18 & $60 \%$ \\
\cline { 2 - 4 } & Fall & 12 & $40 \%$ \\
\cline { 2 - 4 } & Total & 30 & $100 \%$ \\
\cline { 2 - 4 } & $>6$ Days & 13 & $43.34 \%$ \\
\hline \multirow{2}{*}{} & Total & 17 & $100 \%$ \\
\hline
\end{tabular}

In our study of 30 cases, 10 cases were between age group of 25-35 (33.33\%), 9 cases were between age group of 36-45 (30\%), 11 cases were between age group of 46-55 (36.66\%). Eighteen cases (60\%) were male and 12 cases (40\%) were female. The sixteen (53.33\%) patients were operated on the right side and fourteen (46.67\%) patient were operated on left side. Twenty-four cases (80\%) were right side dominant and six cases (20\%) were left side dominant. The mode of injury in eighteen (60\%) cases were road traffic accident and in twelve (40\%) cases were fall. Out of thirty patients thirteen (43.34\%) patients were operated within 6 days and seventeen (56.66\%) patient operated after 6 days from the day of injury, mean $( \pm \mathrm{SD}) 7.2( \pm 2.36)$.

Table 2: Age characteristics of the study group

\begin{tabular}{|c|c|c|}
\hline \multirow{3}{*}{ Age In Years } & Mean \pm Sd & $\mathbf{4 0 . 4 3 ( \pm 9 . 1 3 )}$ \\
\cline { 2 - 3 } & Median & 41.5 \\
\cline { 2 - 3 } & Mode & 29 \\
\hline
\end{tabular}

The Mean $( \pm S D)$ age was $40.43( \pm 9.13)$, median was 41.5 , and mode was 29. Maximum age in the study was 55 and minimum age was 26 .

Table 3: Associated injuries with comminuted radial head fracture

\begin{tabular}{|c|c|c|}
\hline Associated Injury & No. Of Patient & Percentage \\
\hline Lcl Injury & 5 & $16.66 \%$ \\
\hline Mcl Injury & 2 & $6.66 \%$ \\
\hline $\begin{array}{c}\text { Elbow Dislocation + Lcl } \\
\text { Injury+Mcl Injury }\end{array}$ & 8 & $26.66 \%$ \\
\hline Olecrenon Fracture & 2 & $6.66 \%$ \\
\hline No Associated Injury & 13 & $43.33 \%$ \\
\hline
\end{tabular}

In our study of thirty patient with comminuted radial head fracture the five $(16.66 \%)$ patients were associated with lateral collateral ligament injuries, two (6.66\%) patients with medial collateral ligament injuries, eight (26.66\%) with elbow dislocation along with lateral collateral ligament and medial collateral ligament injuries, two (6.66\%) with olecranon fracture.

Table 4: The Modified Mason classification Type III and Type IV

\begin{tabular}{|c|c|c|}
\hline Type & No. of Patient & Percentage \\
\hline Type III & 22 & $73.33 \%$ \\
\hline Type IV & 8 & $26.67 \%$ \\
\hline Total & 30 & $100 \%$ \\
\hline
\end{tabular}

According to The Modified Masons classification, twenty-two
(73.33\%) patients of type III and eight (26.67\%) patients of type IV.

Table 5: Co morbidities and habits characteristics of the study group

\begin{tabular}{|c|c|c|}
\hline Comorbideties & No. of Pateint & Percentage \\
\hline HTN & 3 & $10 \%$ \\
\hline DM & 1 & $3.33 \%$ \\
\hline HTN + DM & 2 & $6.66 \%$ \\
\hline Tobacco & 2 & $6.66 \%$ \\
\hline Smkoing & 4 & $13.33 \%$ \\
\hline
\end{tabular}

In study of 30 cases 2 (6.66\%) patients with diabetes mellitus and hypertension both, 3 (10\%) patients with hypertension and $1(3.33 \%)$ patient with diabetes mellitus. The $4(13.33 \%)$ patients were smokers.

Table 6: Mayo elbow performance index (MEPI) score at $1^{\text {st }}$ month, $3^{\text {rd }}$ month and 6 month

\begin{tabular}{|c|c|c|c|}
\hline $\begin{array}{c}\text { Months of } \\
\text { follow up }\end{array}$ & $\begin{array}{c}\text { AT 1 } \\
\text { Month } \\
\text { Mean }( \pm \text { SD) }\end{array}$ & $\begin{array}{c}\text { AT 3 } \\
\text { Month } \\
\text { Mean }( \pm \text { SD) }\end{array}$ & $\begin{array}{c}\text { AT 6 } \\
\text { Month } \\
\text { Mean }( \pm \text { SD) }\end{array}$ \\
\hline Meps & $80.34( \pm 14.25)$ & $86.64( \pm 11.69)$ & $91.84( \pm 9.86)$ \\
\hline P Value between 1st and 3rd month $<0.001$, 3rd and 6th months
\end{tabular}

$<0.001$ both were statistically significant.

Postoperatively patients were assessed by Mayo elbow performance index (MEPI) score. At follow up of $1^{\text {st }}$ month, the mean $( \pm S D)$ score was $80.34( \pm 14.25)$. At follow up of $3^{\text {rd }}$ month, the mean $( \pm \mathrm{SD})$ score was $86.64( \pm 11.69)$ and at $6^{\text {th }}$ month follow up, the mean $( \pm \mathrm{SD})$ score was $91.84( \pm 9.86)$. At $6^{\text {th }}$ month of follow up Range of movement in average flexion was 140 degrees, average extension deficit was $9^{\circ}$, average pronation was $78^{\circ}$, and average supination was $72^{\circ}$. A difference in the Mayo elbow performance index (MEPI) score at $1^{\text {st }}$ month and $3^{\text {rd }}$ month was statistically significant (P value <0.001). And difference in the Mayo elbow performance index (MEPI) score at $3^{\text {rd }}$ month and $6^{\text {th }}$ months was also statistically significant ( $\mathrm{P}$ value $<0.001$ ).

$1^{\text {st }}$ Post op month $-3^{\text {rd }}$ Post op month: $d f=29$, $p$ value $=$ 0.00, Sig

$3^{\text {rd }}$ Post op month $-6^{\text {th }}$ Post op month: $d f=29$, $p$ value $=$ 0.00, Sig

Table 7: Mayo elbow performance index (MEPI) results

\begin{tabular}{|c|c|c|}
\hline Meps & No. UF patient & Percentage \\
\hline Excellent $(>95)$ & 20 & $66.66 \%$ \\
\hline Good $(75$ to 94$)$ & 8 & $26.66 \%$ \\
\hline Fair $(60$ to 74$)$ & 1 & $3.33 \%$ \\
\hline Poor $(<60)$ & 1 & $3.33 \%$ \\
\hline
\end{tabular}

According to Mayo elbow performance index (MEPI), the 20 cases $(66.67 \%)$ had excellent results, 8 cases $(26.66 \%)$ had good results, 1 case (3.33\%) had fair results, and 1 case (3.33\%) had poor result.

Table 8: Complications after surgery

\begin{tabular}{|c|c|c|}
\hline Complication & No. of patient & Percentage \\
\hline Crps & 1 & $3.33 \%$ \\
\hline Joint stiffness & 1 & $3.33 \%$ \\
\hline No complication & 28 & $93.33 \%$ \\
\hline
\end{tabular}

Thirty patients were operated for radial head arthroplasty out of that 1 patient came with complex regional pain syndrome and according to MEPI the patient had poor result and 1 patient came with elbow joint stiffness at $1^{\text {st }}$ month follow up 
but which improved later to functional range of movement.

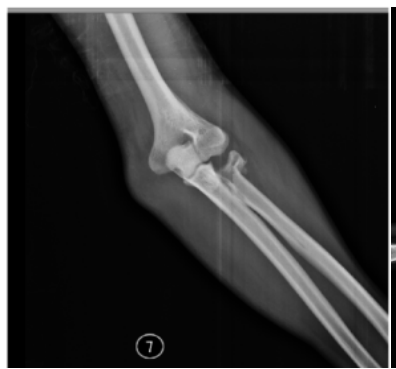

1A: AP view

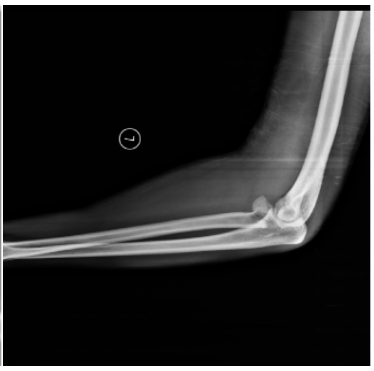

1B: lateral view
Fig 1: Preoperative X-ray

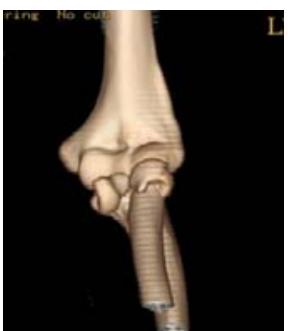

2A

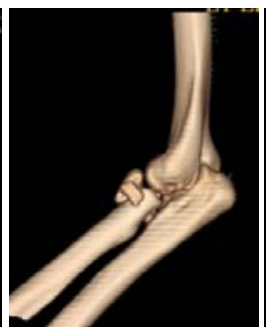

2B

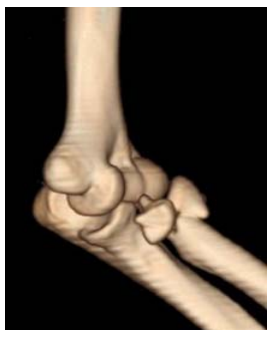

$2 \mathrm{C}$
Fig 2: Preoperative CT scan

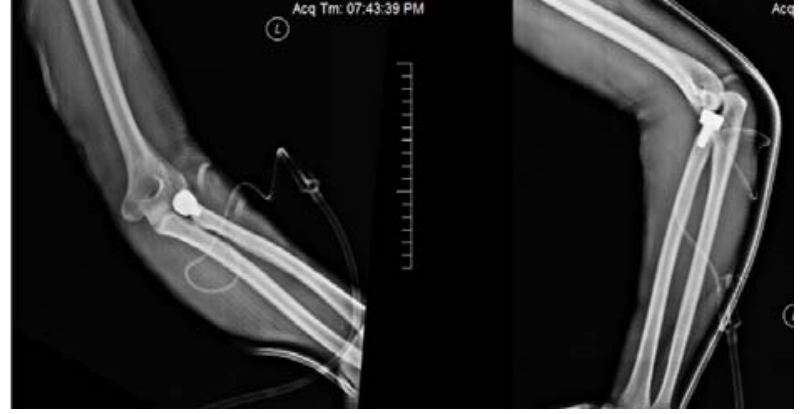

Fig 3: Immediate Post op X-ray AP and Lateral view

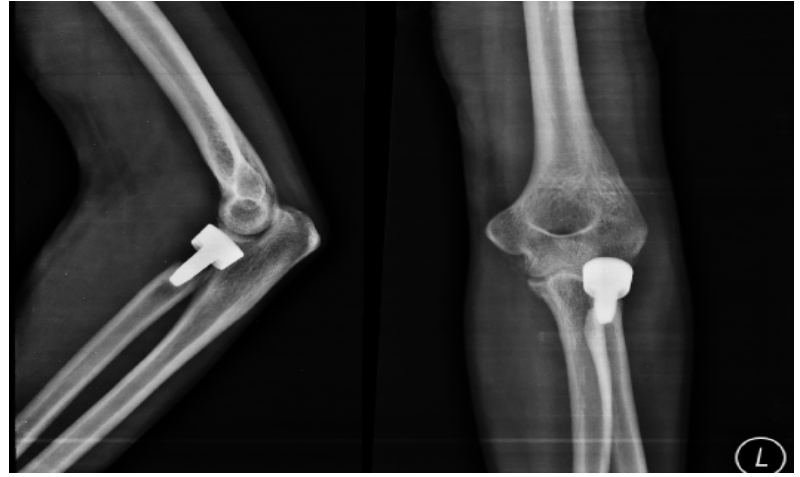

Fig 4: $6^{\text {th }}$ months follow up X-ray AP and Lateral view

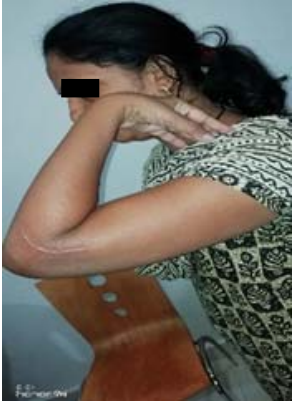

$5 \mathrm{~A}$ (flexion)

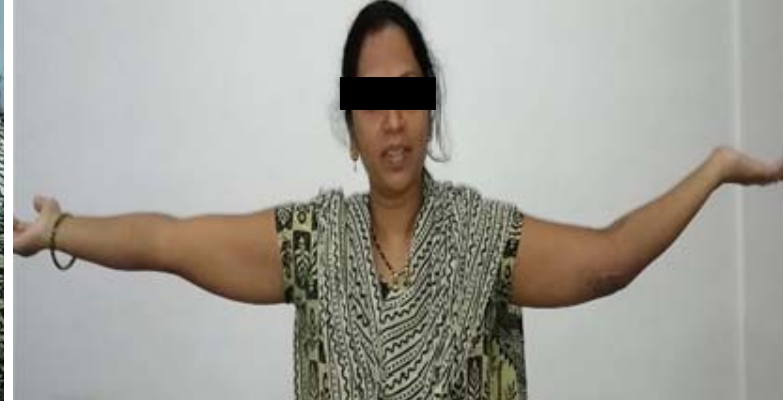

5B (extension)

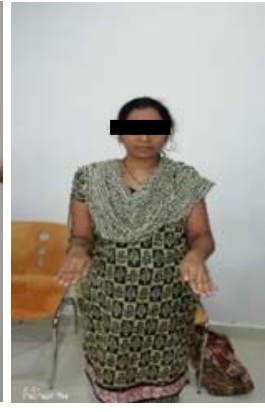

$5 \mathrm{C}$ (pronation)

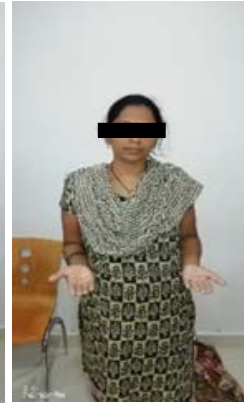

5D (supination)

Fig 5: $6^{\text {th }}$ months follow up Range of movement

\section{Discussion}

Comminuted fractures of the radial head where internal fixation is not possible, simple excision is good option, if there is no other lesion affecting stability of the elbow. ${ }^{[12]}$ It is difficult to diagnose associated damage to the interosseous membrane and radio-ulnar instability in comminuted radial head fracture. ${ }^{[13]}$ Posterior dislocation of the elbow and laxity of the medial ligament are easy to diagnose, as is obvious disruption of the inferior radio-ulnar joint, which should always be part of the radiological assessment of such injuries.

The inappropriate excision of the radial head results symptomatic weakness and instability of the elbow, late cubitus valgus, secondary subluxation or dislocation of the elbow joint and proximal migration of the radius, which will have further consequences for the inferior radio- ulnar joint. In the long-term cases of inappropriate excision of radial head surgery may accelerate the onset of osteoarthritis. Therefore, radial head arthroplasty is indicated if there is instabilities in elbow. Speed in 1941 first proposed prosthetic replacement of the radial head ${ }^{[14]}$. Acrylic radial head prostheses were introduced but were discarded due to fractures of the prosthesis itself. After that Silastic prosthesis was introduced in the 1970s. It acted as a spacer only without giving any biomechanical advantage in weight transmission and also caused synovitis ${ }^{[15-19]}$. The search for a stiffer material for prosthesis manufacture resulted in the use of various metals such as vitallium, stainless steel, and most recently titanium. Literature supports metallic radial head replacement as it restores the axial stiffness of the forearm to normal whereas excision allows abnormal proximal migration, especially under load ${ }^{[20-21]}$.

The results of our series compare with other studies (table 9). Judet et al. ${ }^{[22]}$ conducteda study on 12 patient , 6 male and 6 female, a floating radial head prosthesis for radial head fracture and mean follow up was 49 months, according to this study active flexion averaged $130^{\circ}$, extension deficit averaged $13^{\circ}$, average supination was $74^{\circ}$ and average pronation was 74. According Broberg and Morrey Score 1986 in fresh fractures 2 excellent results and 3 good results, in old fracture 1excellent, 4 good, 2 fair results. Smets et al. ${ }^{[23]}$ reported results from their multicenter trial using a bipolar radial head prosthesis (Tornier Inc., Montbonnot-Saint- Martin, France) after 25.2 months of mean follow-up. In this case study, 13 Mason type III fractures were managed by radial head 
replacements. The average age was 46 years. Smets et al. ${ }^{\text {[23] }}$ reported active flexion averaged $135.5^{\circ}$, extension deficit averaged $16.3^{\circ}$, active pronation averaged $79.3^{\circ}$, and active supination averaged $83^{\circ}$. According to MEPI Score 7 had excellent, 3 had good, 1 had fair and 2 had poor results. One patient with a poor result required removal of prosthesis. Moro et al. ${ }^{[24]}$ completed a retrospective study of 10 patients with Mason type III fractures treated with radial head replacements (Smith and Nephew Richards, Memphis, TN, USA) over an average of 2 years. The average age was 47 years. Moro et al. ${ }^{[24]}$ reported both assessments comparing the function of the injured arm with the contralateral arm. Average pronation was $78^{\circ}$ compared to $79^{\circ}$, supination $69^{\circ}$ compared to $77^{\circ}$, elbow flexion $140^{\circ}$ compared to $143^{\circ}$, and elbow extension deficit was $8^{\circ}$ compared to full extension on the uninjured side $(P<0.05)$. In our study, average flexion was $140^{\circ}$, average extension deficit was $9^{\circ}$, average pronation was $78^{\circ}$, and average supination was $72^{\circ}$. According Moro et al. ${ }^{[24]}$ study six patients suffered complications, including elbow stiffness, ulnar nerve dysesthesia, varying levels of heterotopic ossification, one superficial infection and one patient developed a regional sympathetic -mediated pain syndrome. Accordingly the MEPI score 17 patients had good results, 5 patients had fair results and 3 patients had poor results. Popovic et al. ${ }^{[25]}$ conducted a study on 11 patient with the mean follow up 32 months, according to MEPI score, 4 cases had excellent results, 4 cases good results, 2 cases fair results and 1 case had poor result. In our study of 30 patients, At $6^{\text {th }}$ month of follow up Range of movement in average flexion was 140 degrees, average extension deficit was $9^{\circ}$, average pronation was $78^{\circ}$, and average supination was $72^{\circ}$. According to MEPI score, 20 cases had excellent results, 8 cases good results, 1 case fair result and 1 case had poor result. One patient had developed complex regional pain syndrome and one had elbow joint stiffness.

\section{Conclusion}

Radial head arthroplasty can be used successfully with most of excellent results for treatment of Comminuted radial head fracture (The Modified Mason classification type III and IV radial head fractures). This study is not without limitations. Even though it is prospective study, patients were followed for shorter duration only. Hence, a study with elegant methodology and long follow up period can accurately assess the efficacy of the radial head prosthesis used in radial head arthroplasty.

Ethical Approval: The study was approved by the institutional ethics committee.

\section{Reference}

1. Mabit C. Fractures récentes et anciennes de la tête radiale. Annales Orthop de l'Ouest, 1994; 26:151-93.

2. Hotchkiss RN. Displaced fractures of the radial head: Internal fixation or excision? J Am Acad Orthop Surg. 1997; 5:1-10.

3. Morrey BF, Chao EY, Hui FC. Biomechanical study of the elbow following excision of the radial head. J Bone Joint Surg Am. 1979; 61:63-8.

4. Bucholz RW, Court-Brown CM, Heckman JD, Tornette P. Rockwood and Green's Fractures in Adults. 7th ed. Philadelphia: Lippincott Williams and Wilkins, 2010, 911-8.

5. Z Orthop Unfall. DOI: 10.1055/s-0042-118960. Epub, 2017; 155(2):220-225.
6. King GWJ, Evans DC, Kellam JF. Open reduction and internal fixation of radial head fractures. J Orthop Trauma 1991; 5:21-8.

7. Coleman DA, Blair WF, Shurr D. Resection of the radial head for fracture of the radial head: long-term follow-up of seventeen cases. J Bone Joint Surg [Am]1987; 69A:385-92.

8. Janssen RP, Vegter J. Resection of the radial head after Mason type III fractures of the elbow: follow-up at 16 to 30 years. J Bone Joint Surg [Br], 1998; 80-B:231-3.

9. Morrey BF, Tanaka S, An KN. Valgus stability of the elbow: a definition of primary and secondary constraints. Clin Orthop1991; 265:187-95.

10. Morrey BF. Current concepts

11. In the treatment of the fractures of the radial head, the olecranon, and the corono id. InstrCourseLect. 1995; 44:175-85.

12. Sowa DT, Hotch kiss RN, Weil and AJ. Symptom aticproximaltranslaton of the radius following gradial head resection. ClinOrthop, 1995; 317:106-13.

13. GoldbergI, PeylandJ, Yosipovitch Z. Late results of excision of the radial head for anisolated fracture. JBoneJointSurg[Am], 1986;68-A:675-9.

14. Wallace AL, Walsh WR, van Rooiken M, Hughes J, Sonnabend $\mathrm{DH}$. The interosseous membrane in radioulnardissociation. JBoneJointSurg[Br], 1997;79-B:422-7.

15. Speed K. Ferrule caps for the head of the radius. Surg Gynecol Obstet. 1941; 73:845-50.

16. Hotchkiss RN, Weiland AJ. Valgus stability of the elbow. J Orthop Res. 1987; 5:372-7.

17. Carn RM, Medige J, Curtain D, Koenig A. Silicone rubber replacement of the severely fractured radial head. Clin Orthop Relat Res. 1986; 209:259-69.

18. Stoffelen DV, Holdsworth BJ. Excision or Silastic replacement for comminuted radial head fractures. A long-term follow-up. Acta Orthop Belg. 1994; 60:402-7.

19. Vanderwilde RS, Morrey BF, Melberg MW, Vinh TN. Inflammatory arthritis after failure of silicone rubber replacement of the radial head. J Bone Joint Surg Br. 1994; 76:78-81.

20. Pribyl CR, Kester MA, Cook SD, Edmunds JO, Brunet ME. The effect of the radial head and prosthetic radial head replacement on resisting valgus stress at the elbow. Orthopedics. 1986; 9:723-6. [PUBMED]

21. Ashwood N, Bain GI, Unni R. Management of Mason type-III radial head fractures with a titanium prosthesis, ligament repair, and early mobilization. J Bone Joint Surg Am. 2004; 86-A: 274-80.

22. Bain GI, Ashwood N, Baird R, Unni R. Management of Mason type-III radial head fractures with a titanium prosthesis, ligament repair, and early mobilization. Surgical technique. J Bone Joint Surg Am. 2005; 87, 1(Pt 1):136-

23. Judet T, Garreaude Loubresse C, Pirious P, Charnley G. A floating pros thesis for radial-head fractures. JBoneJointSurg[Br],1996; 78-B:244-9.

24. Smets S, Govaers K, Jansen N, Van Riet R, Schaap M, Van Glabbeek F. The floating radial head prosthesis for comminuted radial head fractures: A multicentric study. Acta Orthop Belg. 2000; 66:353-8.

25. Moro JK, Werier J, MacDermid JC, Patterson SD, King GJ. Arthroplasty with a metal radial head for unreconstructible fractures of the radial head. J Bone Joint Surg Am. 2001; 83-A: 1201-11.

26. Popovic N, Gillet P, Rodriguez A, Lemaire R. Fracture of 
the radial head with associated elbow dislocation: results

of treatment using a floating radial head pros- thesis. J

Orthop Trauma 2000; 14:171-7. 